\title{
Imaginologia aplicada à reprodução de animais selvagens
}

Leandro Nassar Coutinho

Universidade Federal Rural da Amazônia (UFRA)

ISSUE DOI: $10.3738 / 1982.2278 .1134$

A crescente demanda de atendimento de animais selvagens na clínica veterinária exige um conhecimento anátomofisiológico amplo sobre as diversas espécies existentes na nossa fauna ou até mesmo de animais exóticos. O diagnóstico clínico de enfermidades reprodutivas ou acompanhamento gestacional nesses animais é em geral bastante complexo, visto que o médico veterinário em grande parte das ocasiões não pode contar com um histórico completo dos animais atendidos, que muitas vezes são oriundos de práticas ilegais de comércio ou áreas de conservação ou manutenção de espécimes em vida livre ou em cativeiro. Em outra ótica, o estabelecimento de alguns animais selvagens, como animais de companhia, tem desafiado os profissionais da área ao conhecimento fisiológico e ao diagnóstico de enfermidades em um grupo cada vez maior de espécies. Com, isso não só o aspecto conservacionista, mas também o interesse econômico por trás de novas atividades comerciais estão modificando o manejo e criação de espécies selvagens. Dentre as práticas de manejo e dentre os estudos das afecções mais recorrentes, estão as relacionadas ao aparelho reprodutor e a gestação ou procriação. Diante disso, os exames complementares passam a ter grande papel na clínica reprodutiva de animais selvagens. Os métodos de diagnóstico por imagem figuram com destaque, entre os mais elucidativos e por isso o conhecimento anatômico e da anatomia radiológica e ultrassonográfica são fundamentais. O diagnóstico por imagem tem a característica de ser um conjunto de técnicas minimamente ou não invasivas, que permitem a obtenção de informações em tempo real ou avaliar o perfil de atividades reprodutivas ao longo do tempo. Com o objetivo de apresentar os principais métodos de imagem utilizados para o diagnóstico de enfermidades em animais selvagens, incluindo técnicas radiográficas, ultrassonográficas e noções de Videoendoscopia, Tomografia Computadorizada e Ressonância Magnética, esperamos que a apresentação permita o entendimento dos equipamentos utilizados, metodologia das técnicas de imagem e diagnóstico diferenciais de afecções reprodutivas em mamíferos, répteis, anfíbios e aves selvagens.

Palavras-chave: Anatomia, Enfermidades, Radiologia, Ultrassonografia, Videoendoscopia. 